\title{
Kelayakan Teknologi Desalinasi Sebagai Alternatif Penyediaan Air Minum Kota Surabaya (Studi Kasus: 50 Liter per detik)
}

\author{
Nurul Latifa Hanna dan Wahyono Hadi \\ Jurusan Teknik Lingkungan, Fakultas Teknik Sipil dan Perencanaan, \\ Institut Teknologi Sepuluh Nopember (ITS) \\ Jl. Arief Rahman Hakim, Surabaya 60111 Indonesia \\ e-mail:wahyono@enviro.its.ac.id
}

\begin{abstract}
Abstrak-Saat ini, PDAM Surabaya masih kesulitan mencari air baku. Selain kurangnya debit untuk air baku, kualitas air baku di Surabaya yang minim membuat biaya produksi semakin meningkat. Di sisi lain, masih terdapat air laut sebagai sumber air baku yang secara kuantitas tidak terbatas namun memiliki kadar garam yang sangat tinggi. Dikaji 3 alternatif teknologi pengolahan yang umum digunakan secara studi literatur, yaitu: teknologi distilasi dengan Multi Stage Flash Distilation (MSF), teknologi membran dengan Reverse Osmosis (RO) dan teknologi pertukaran ion dengan (Electrodeionization). Unit pengolahan yang terpilih adalah Reverse Osmosis dengan keunggulan terletak pada kecepatannya dalam memproduksi air serta adanya peluang pemanfaatan reject water yang dapat meringankan biaya investasi yang sangat tinggi. Unit pengolahan terdiri dari vertical beach-well intake, koagulasi-flokulasi, sedimentasi, pressure sand filter, karbon aktif, RO dan terakhir klorinasi. Pengolahan ini tidak menggunakan bahan kimia, sehingga reject water dapat dimanfaatkan menjadi garam murni dan nigari yang aman untuk dikonsumsi. Hasil analisa finansial dari sistem pengolahan ini dapat dikatakan layak karena memiliki nilai NPV bernilai positif sebesar Rp11.953.760.829 dengan IRR sebesar $\mathbf{2 8 , 8 1 \%}$ yang lebih besar dari MARR Bank BNI yaitu $\mathbf{1 2 , 5 \%}$ dengan periode pengembalian setelah 6 tahun proyek berjalan berdasarkan metode payback period.
\end{abstract}

Kata Kunci-analisa kelayakan, desalinasi, Pantai Kenjeran, penyediaan air minum, Reverse Osmosis

\section{PENDAHULUAN}

$\mathrm{K}^{\circ}$ OTA Surabaya sendiri menjadi kota yang paling diincar para pengembang untuk mendirikan apartemen. Banyak penduduk luar Kota Surabaya yang ingin tinggal di Surabaya karena pekerjaan atau bisnis yang dimiliki. Berdasarkan Colliers International Indonesia Research, tercatat akan terdapat sebanyak 25.500 unit apartemen yang ada di Kota Surabaya pada tahun 2018 [1]. Kenaikan sebesar 10,8\% terjadi pada tahun 2014. Kenaikan terjadi hanya dalam 1 semester [1]. Sehingga, tidak heran apabila jumlah kebutuhan air di Surabaya meningkat.

Air baku PDAM berasal dari Sungai Brantas. Pada tahun 2014, sambungan rumah PDAM Surabaya tercatat 483.875 rumah dengan total penduduk 2.853.661 jiwa [2]. Itu berarti produksi PDAM hanya bisa melayani $70 \%$ dari total masyarakat Surabaya. Perusahaan Daerah Air Minum (PDAM) Surya Sembada Surabaya mengeluhkan kualitas air baku di Surabaya yang masih minim. Penyebab buruknya kualitas air ini karena lokasi Surabaya berada di hilir. Hal ini otomatis membuat biaya produksi menjadi lebih tinggi karena menanggung beban penjernihan air yang tercemar. Biaya produksi dari PDAM kini mencapai Rp 2.100,- per meter kubik [3].

Walikota Surabaya, Tri Risma Harini merencanakan untuk membangun pintu air baru di hilir Sungai Surabaya sebagai upaya mengatasi defisit air baku air minum warga Kota Surabaya [4]. Namun, solusi tersebut belum dapat menyelesaikan permasalahan mengenai kualitas air baku yang terus menurun yang menyebabkan air hasil produksi tidak layak minum dan kuantitas yang tidak menentu karena tergantung pada musim.

Sumber air yang secara kuantitas tidak terbatas adalah air laut. Akan tetapi air laut mengandung kadar garam dan TDS (Total Dissolved Solid) yang sangat tinggi sehingga diperlukan pengolahan lebih lanjut agar dapat dimanfaatkan sebagai air minum [5]. Sehingga diperlukan pengkajian khusus mengenai pengolahan air laut yang biasa disebut dengan desalinasi. Pengkajian akan dilakukan terhadap 3 alternatif pengolahan yang umum digunakan oleh para produsen air minum di dunia, yaitu teknologi distilasi dengan Multi Stage Flash Distilation (MSF), teknologi membran dengan Reverse Osmosis (RO) dan teknologi pertukaran ion dengan (Electrodeionization). Teknologi terpilih akan direncanakan sesuai dengan hasil kualitas air laut di Surabaya. Sehingga didapatkan teknologi yang tepat untuk diaplikasikan dan layak secara finasial.

\section{URAIAN PERENCANAAN}

\section{A. Studi Literatur}

Studi literatur dilakukan untuk mengkaji setiap alternatif pengolahan, pengkajian dilakukan dengan beberapa aspek teknis dan finansial.

Sumber literatur yang digunakan antara lain adalah jurnal, chapter book, prosiding, text book dan peraturan pemerintah maupun SNI yang berlaku.

\section{B. Pengumpulan Data}

Pengumpulan data terbagi menjadi 2, yaitu: pengumpulan data sekunder dan primer. Data primer adalah data yang didapatkan langsung, yaitu saat pengambilan sampel. Sampel adalah air laut di wilayah Surabaya.

Alat yang diperlukan saat pengambilan sampel adalah botol 
plastik 1,5 L. Diambil air sampel dari sumber sebanyak 1,5 liter sebanyak 2 botol. botol diisi penuh sampai tidak terdapat udara dalam botol. Air baku diambil dengan menggali pasir sedalam $\pm 0,5$ meter.

Data Sekunder adalah data yang berdasarkan pada referensi yang ada. Data yang dibutuhkan dalam studi ini adalah Harga Satuan Pokok (HSPK) dan baku mutu air minum berdasarkan Peraturan Menteri Kesehatan Republik Indonesia Nomor 492/MENKES/PER/IV/2010.

\section{Pengolahan Data}

Pengolahan data dilakukan dengan pengujian laboratorium. Uji laboratorium akan dilakukan dengan menguji kualitas air baku dari 8 parameter dengan masing-masing metode. Terdapat parameter yang melebihi syarat air minum PERMENKES RI No. 492MENKES/PER/IV/2010

\section{Pengkajian Alternatif Teknologi Pengolahan}

Dikaji 3 alternatif teknologi berdasarkan studi literatur. Tabel 1.

Metode Uji Laboratorium

\begin{tabular}{ll}
\hline \hline \multicolumn{1}{c}{ Parameter } & \multicolumn{1}{c}{ Metode } \\
\hline TOC & TOC Analyzer \\
Timbal & Spektrofotometri Serapan Atom (SSA) \\
Kadmium & Spektrofotometri Serapan Atom (SSA) \\
Klorin & Metode iodometri \\
Salinitas & Handy-lab LF11 \\
TDS & Handy-lab LF11 \\
Kekeruhan & Uji kekeruhan dengan Nefelometer \\
pH & pH meter \\
Suhu & Termometer \\
\hline \hline
\end{tabular}

Pengkajian dilakukan dengan beberapa aspek teknis dan finansial, yaitu :

1. Kualitas setiap pengolahan

2. Kebutuhan lahan

3. Daya listrik

4. Biaya kapital dan biaya produksi

\section{E. Pemilihan Alternatif Teknologi}

Pemilihan teknologi berdasarkan penilaian poin. Poin diberikan berdasarkan urutan dari yang paling tidak direkomendasikan sampai paling direkomendasikan. Diberikan nilai dari yang terendah adalah 5 , nilai sedang adalah 15 dan yang tertinggi adalah 30 poin. Poin akan dijumlahkan pada masing-masing alternatif teknologi. Sehingga didapatkan nilai yang paling tinggi ada teknologi yang terpilih.

\section{F. Perhitungan Dimensi Unit Pengolahan}

Perhitungan dilakukan sesuai dengan unit yang terpilih. Perhitungan juga meliputi perhitungan dimensi unit tambahan yang dibutuhkan, baik pre-treatment maupun post-treatment.

\section{G. Analisa Finansial}

Analisa finansial meliputi beberapa aspek, yaitu:

1. Biaya Pengeluaran

- $\quad$ Biaya investasi $=$ Total RAB
- $\quad$ Biaya cicilan $=\left[\frac{i(1+i)^{N}}{(1+i)^{N}-1}\right]$

- Biaya operasional dan pengelolaan limbah B3

- Biaya listrik, sewa lahan dan gaji karyawan

2. Biaya pemasukan meliputi: Air produksi, garam murni dan nigari

3. Net Present Value $=\sum_{t}^{N} \frac{R t}{(1+i)^{t}}$

4. Internal Rate of Return (IRR)

- $\quad \mathrm{NPW}=\mathrm{PW}_{\mathrm{R}}-\mathrm{PW}_{\mathrm{E}}$

- $\mathrm{P} / \mathrm{F}=\left[\frac{1}{(1+i)^{N}}\right]$

5. Payback Period

$$
\text { - } \mathrm{N}=\frac{P}{A t}
$$

Keterangan:

$\mathrm{N}=$ total umur proyek atau periode studi proyek

$\mathrm{Rt}=$ aliran kas masuk, aliran kas keluar

$\mathrm{t}$ = waktu pada aliran kas

$\mathrm{i}$ = besarnya nilai MARR $(\%)$

NPW $=$ Net Present Worth

$\mathrm{PW}_{\mathrm{R}}=$ Nilai Present Worth aliran kas positif

$\mathrm{PW}_{\mathrm{E}}=$ Nilai Present Worth aliran kas negatif

$\mathrm{P}=$ Biaya investasi

$\mathrm{At}=$ Aliran kas

\section{HASIL DAN PEMBAHASAN}

\section{A. Kualitas Air Laut Kota Surabaya}

Terdapat beberapa parameter yang tidak memenuhi baku mutu. Berikut hasil analisis kualitas air laut:

\section{B. Alternatif Pengolahan dengan Teknologi MSF}

Teknologi desalinasi dengan menggunakan distilasi atau

Tabel 2.

Hasil Analisis Kualitas Air Laut Pantai Kenjeran

\begin{tabular}{llll}
\hline \hline Parameter & \multicolumn{1}{c}{ Metode } & Hasil Uji & Keterangan \\
\hline TOC & TOC Analyzer & $0,387 \mathrm{mg} / \mathrm{L}$ & $\begin{array}{l}\text { Tidak } \\
\text { memenuhi }\end{array}$ \\
Timbal & $\begin{array}{l}\text { Spektrofotometri } \\
\text { Serapan Atom (SSA) } \\
\text { Kadmium }\end{array}$ & $1,287 \mathrm{ppm}$ & $\begin{array}{l}\text { Tidak } \\
\text { memenuhi }\end{array}$ \\
& $\begin{array}{l}\text { Spektrofotometri } \\
\text { Serapan Atom (SSA) }\end{array}$ & $0,0014 \mathrm{ppm}$ & Memenuhi \\
Klorin & Metode iodometri & $21 \%$ & $\begin{array}{l}\text { Tidak } \\
\text { memenuhi }\end{array}$ \\
Salinitas & Handy-lab LF11 & $23,9 \%$ & $\begin{array}{l}\text { Tidak } \\
\text { memenuhi }\end{array}$ \\
TDS & Handy-lab LF11 & $33960 \mathrm{mg} / \mathrm{L}$ & $\begin{array}{l}\text { Tidak } \\
\text { memenuhi }\end{array}$ \\
Kekeruhan & Uji kekeruhan dengan & $12 \mathrm{NTU}$ & $\begin{array}{l}\text { Tidak } \\
\text { memenuhi } \\
\text { pH }\end{array}$ \\
$\begin{array}{l}\text { Nefelometer } \\
\text { pH meter }\end{array}$ & 7,78 & $\begin{array}{l}\text { Memenuhi } \\
\text { Memenuhi }\end{array}$ \\
\hline \hline
\end{tabular}

dengan menggunakan energi panas telah digunakan ratusan tahun yang lalu. Namun dalam skala besar untuk perkotaan, pengolahan dengan teknologi desalinasi mulai beroperasi sekitar tahun 1950an [7].

Kebutuhan air intake untuk pengolahan pada MSF sangat besar, mencapai 6-8 kapasitas air produksi. Semakin besar 
debit yang diolah akan semakin besar energi panas yang dibutuhkan serta semakin luas lahan yang dibutuhkan untuk instalasi pengolahan. Namun untuk kualitas air olahan tidak tegantung pada kondisi TDS air baku, yaitu kurang lebih 5 $\mathrm{mg} / \mathrm{L}$ karena air olahan adalah hasil dari penguapan [8]. Pembangunan instalasi ini membutuhkan pembangunan pondasi dan pengerjaan konstruksi sipil yang ekstensif, sehingga untuk penambahan kapasitas olahan akan cukup sulit [9].

Sebuah instalasi MSF dengan kapasitas 6 mgd (263 L/detik) dengan TDS 50.000 ppm pada suhu $110^{\circ} \mathrm{C}$ mengkonsumsi sekitar $75 \mathrm{MW}$ energi panas $\left(285 \mathrm{MW} / \mathrm{m}^{3}\right)$ dan sekitar $3 \mathrm{MWe}$ untuk resirkulasi saja dan 1.2 MWe untuk pompa. Rata-rata membutuhkan listrik $2,5-4 \mathrm{KWh} / \mathrm{m}^{3}$ [10]. Pembangunan instalasi MSF dengan kapasitas 6 mgd membutuhkan biaya capital sebesar \$ 84.350.000 (Rp 1,1 Trililliun) [10] dengan biaya produksi sebesar $\$ 0.584 / \mathrm{m}^{3}(\operatorname{Rp} 7.690,70)$ [11].

\section{Alternatif Pengolahan dengan Teknologi RO}

Apabila terdapat dua larutan dengan konsentrasi rendah dan konsentrasi tinggi dipisahkan oleh membran semi permeable, maka larutan dengan konsentrasi yang rendah akan terdisfusi melalui membran semi permeable tersebut masuk ke dalam larutan konsentrasi tinggi sampai terjadi kesetimbangan konsentrasi. Fenomena tersebut dikenal sebagai proses osmosis. Ketika terdapat suatu sistem osmosis diberi tekanan yang lebih besar dari tekanan osmosisnya $\left(32,1 \mathrm{~kg} / \mathrm{m}^{2}\right.$ untuk TDS $42.000 \mathrm{ppm}$ pada suhu $30^{\circ} \mathrm{C}$ dan $26,7 \mathrm{~kg} / \mathrm{cm}^{2}$ untuk TDS 35000 ppm pada suhu $25^{\circ} \mathrm{C}$ ), maka aliran air tawar akan berbalik yakni dari air asin ke air tawar melalui membran semi permeable, sedangkan garamnya tetap tertinggal di dalam larutan garamnya sehingga menjadi lebih pekat [8]. Kapasitas debit air baku pada umumnya \pm 3 kali lipat dari kapasitas sistem Reverse Osmosis, dimana sepertiganya akan diolah menjadi air tawar dan sisanya sebagai reject untuk membuang garamnya [5].

Terdapat 2 jenis membran Reverse Osmosis (RO) yaitu Seawater Reverse Osmosis (SWRO) dan Breackish Water Reverse Osmosis (BWRO). SWRO digunakan untuk mengolah air dengan rentang TDS $10.000-60.000 \mathrm{mg} / \mathrm{liter}$. BWRO digunakan untuk mengolah air dengan rentang TDS $1.000-10.000 \mathrm{mg} /$ liter [12]. Beberapa membran ketika dioperasikan dalam kondisi yang sesuai dengan standar (32.000 mg/liter $\mathrm{NaCl}, 5,5 \mathrm{MPa}, 25{ }^{\circ} \mathrm{C}, \mathrm{pH} 8$ dan $8 \%$ recovery) dapat menyingkirkan kandungan garam 99,7 $99.8 \%$ [13].

Instalasi RO dengan kapasitas 6 mgd (263 L/detik) dengan TDS 50.000 ppm mengkonsumsi sekitar 14,29 MW energy listrik dan sekitar $45,7 \mathrm{KJ} / \mathrm{kg}$ air laut [10]. Pembangunan instalasi RO dengan kapasitas 6 mgd membutuhkan biaya capital sebesar \$41.000.000 (Rp 540 miliar) dengan biaya produksi sebesar $\$ 0.55 / \mathrm{m}^{3}(\operatorname{Rp} 7.242,95)$ [12].

\section{Alternatif Pengolahan dengan Teknologi EDI}

Electrodeionization merupakan teknologi terdepan yang dapat menghasilkan ultrapure water. Teknologi ini merupakan gabungan dari metode electrodialisis dan ion exchange. Air akan memasuki suatu unit yang terdiri dari membran pertukaran ion, resin pertukaran ion dan juga aliran listrik. Pengolahan ini unggul karena tidak terdapat penggunaan bahan kimia dalam prosesnya dan juga membutuhkan daya listrik yang kecil yaitu $0,25 \mathrm{kWh} / \mathrm{m}^{3}$. Namun daya listrik akan meningkat ketika debit menjadi dua kali lipat [14].

Kualitas air baku unit EDI terbatas pada TDS dan substansi lemah seperti $\mathrm{CO}_{2}$ dan $\mathrm{SiO}_{2}$, selain itu air baku juga harus free chlorine (kadar chlorine harus $<0.1,0.05$, and $0.025 \mathrm{mg} / \mathrm{liter}$ untuk besaran konversi 80, 85 dan 95\%); besi, mangan dan sulfat $<0.01 \mathrm{mgliter}$; rentang $\mathrm{pH} 4-11$; TOC $<0.5 \mathrm{mg} / \mathrm{liter}$ and kesadahan < $1.0 \mathrm{mg} /$ liter for $\mathrm{CaCO} 3$ [15]. Tingkat removal EDI biasanya konstan, yaitu 95\%. Sehingga, pada umumnya teknologi EDI digabungkan dengan teknologi RO. Ketika air konsentrat EDI diolah dengan menggunakan RO, maka efisiensi bisa menjadi 99\% [15]. Teknologi ini sangat optimal untuk meremoval senyawa ion, $\mathrm{CO}_{2}$, silika dan boron [16]. Namun instalasi EDI pada umumnya terdiri dari standar modul, dengan output kategori rendah $11 \mathrm{~m}^{3} / \mathrm{jam}$, kategori sedang $44 \mathrm{~m}^{3} / \mathrm{jam}$ dan kategori tinggi $132 \mathrm{~m}^{3} / \mathrm{jam}$ [14]. Sehingga membutuhkan parallel beberapa modul saat pengoperasiannya

Biaya kapital untuk $132 \mathrm{~m}^{3} / \mathrm{jam}$ dengan TDS $24,9 \mathrm{ppm}$ adalah $\$ 385.000$ (Rp 5,1 miliar) atau setara dengan $\mathrm{Rp} 43,6$ miliar untuk kapasitas $6 \mathrm{mgd}\left(1136.9 \mathrm{~m}^{3} / \mathrm{jam}\right)$ [15]. Pada pengoperasian RO-EDI biaya kapital untuk 108,5 $\mathrm{m}^{3} / \mathrm{jam}$ dengan TDS 30,5 ppm sebesar \$1.124.816,00 (Rp 14,8 miliar) atau setara dengan Rp 155,2 miliar untuk kapasitas 6 mgd $\left(1136.9 \mathrm{~m}^{3} / \mathrm{jam}\right)$ [17]. Sedangkan untuk biaya produksi pada umumnya sebesar $\$ 0.53 / \mathrm{m}^{3}(\mathrm{Rp} 6.979,57)$ [14].

\section{E. Teknologi Terpilih}

Berdasarkan hasil pengkajian, pada tugas akhir ini dipilih teknologi Reverse Osmosis sebagai alternatif yang paling efisien. Hasil nilai pada tabel 3 dapat dilihat bahwa total nilai untuk teknologi MSF sebesar 110, untuk teknologi RO sebesar 135, sedangkan untuk teknologi EDI sebesar 105. Nilai tertinggi jatuh pada teknologi Reverse Osmosis.

Perencanaan ini memilih Reverse Osmosis (RO) sebagai teknologi yang terpilih. Karena biaya yang mahal untuk desalinasi dapat ditutupi dengan hasil jual reject water yang dimanfaatkan sebagai produk garam murni dan air nigari.

Pengolahan menggunakan RO memiliki beberapa persyaratan, yaitu kekeruhan 0 , kandungan organik dan logam $<0,1 \mathrm{mg} / \mathrm{L}$, tidak terdapat warna dan $\mathrm{pH}$ normal. Sehingga, instalasi ini membutuhkan pre-treatment, karena masih terdapat kekeruhan serta kandungan organik dan logam yang terkandung dalam data kualitas air baku. Air yang akan masuk pada instalasi RO tidak mengandung logam berat dan organik, murni hanya kandungan garam. Sehingga dapat dimanfaatkan sebagai produk sampingan yang dapat menambah pemasukan dan menekan biaya produksi.

Pengolahan terdiri dari 3 tahap.

- Pre-treatment

Air baku diambil melalui horizontal beach-well. Sehingga air yang dihasilkan lebih jernih daripada air permukaan. Air tersebut dikumpulkan pada collection well yang 
Tabel 3.

Tabel Perbandingan Teknologi Desalinasi

\begin{tabular}{|c|c|c|c|}
\hline Kategori & MSF & RO & EDI \\
\hline \multirow{3}{*}{$\begin{array}{l}\text { Kebutuhan } \\
\text { lahan }\end{array}$} & Outdoor & Indoor & Indoor \\
\hline & $\begin{array}{l}\text { Lahan yang } \\
\text { sangat luas } \\
\text { karena intake } \\
\text { yang sangat } \\
\text { besar 6-8x air } \\
\text { produksI }\end{array}$ & $\begin{array}{l}\text { Air, } 1.5-3 \text { kali } \\
\text { dari air tawar } \\
\text { yang } \\
\text { dihasilkan }\end{array}$ & $\begin{array}{l}\text { Kapasitas terdiri dari } \\
\text { standar modul, } \\
\text { dengan output } 11 \\
\mathrm{~m}^{3} / \mathrm{h}, 44 \mathrm{~m}^{3} / \mathrm{h} \text { dan } \\
132 \mathrm{~m}^{3} / \mathrm{h}\end{array}$ \\
\hline & $\begin{array}{l}\text { Tidak ada batas } \\
\text { ukuran, dapat } \\
\text { mencapai } \\
100.000 \text { ton/hari }\end{array}$ & $\begin{array}{l}\text { Penambahan } \\
\text { kapasitas } \\
\text { dengan } \\
\text { penambahan } \\
\text { modul }\end{array}$ & $\begin{array}{l}\text { Penambahan } \\
\text { kapasitas dengan } \\
\text { penambahan modul }\end{array}$ \\
\hline Nilai & 5 & 30 & 15 \\
\hline Feed Water & $\begin{array}{l}\text { Kualitas buruk } \\
\text { tidak } \\
\text { mempengaruhi } \\
\text { produksi }\end{array}$ & $\begin{array}{l}\text { Kekeruhan } 0 \text {, } \\
\text { logam dan } \\
\text { organik } \\
<0,01 \mathrm{mg} / \mathrm{L}\end{array}$ & $\begin{array}{l}\text { Bebas klorin; besi, } \\
\text { mangan dan sulfat < } \\
0.01 \mathrm{mgliter} \\
\text { rentang } \mathrm{pH} 4-11 \text {; } \\
\text { TOC < } 0.5 \mathrm{mg} / \mathrm{liter} \\
\text { dan kesadahan }<1.0 \\
\mathrm{mg} / \text { liter for } \mathrm{CaCO} 3\end{array}$ \\
\hline Nilai & 30 & 15 & 5 \\
\hline $\begin{array}{l}\text { Kualitas } \\
\text { produksi }\end{array}$ & $\begin{array}{l}\text { TDS outlet } \pm 5 \\
\text { mg/L. Dengan } \\
\text { hasil yang stabil } \\
\text { tidak tergantung } \\
\text { feed water }\end{array}$ & $\begin{array}{l}\text { Persen } \\
\text { removal tidak } \\
\text { tergantung } \\
\text { besaran TDS, } \\
\text { rata-rata 99\% }\end{array}$ & $\begin{array}{l}\text { Persen removal } \\
\text { semakin kecil } \\
\text { seiring dengan } \\
\text { meningkatnya TDS }\end{array}$ \\
\hline Nilai & 30 & 15 & 5 \\
\hline Daya listrik & $\begin{array}{l}\text { Konsumsi } \\
\text { listrik sekitar } 4 \\
\mathrm{Kwh} / \mathrm{m}^{3} \mathrm{dan} \\
285 \mathrm{MW} / \mathrm{m}^{3} \\
\text { untuk energi } \\
\text { panas }\end{array}$ & $\begin{array}{l}\text { Sekitar 12,7 } \\
\text { Kwh/m } / \mathrm{m}^{3}\end{array}$ & $\begin{array}{l}\text { Rata-rata } 0,25 \\
\mathrm{kWh} / \mathrm{m}^{3}\end{array}$ \\
\hline Nilai & 5 & 15 & 30 \\
\hline $\begin{array}{l}\text { Pre } \\
\text { treatment }\end{array}$ & $\begin{array}{l}\text { Tanpa pre } \\
\text { treatment }\end{array}$ & $\begin{array}{l}\text { Filter, } \\
\text { peremoval } \\
\text { logam dan } \\
\text { organik }\end{array}$ & $\begin{array}{l}\text { Kombinasi alat } \\
\text { penurun TDS (RO), } \\
\text { peremoval logam, } \\
\text { organik, klorin dan } \\
\text { kesadahan }\end{array}$ \\
\hline Nilai & 30 & 15 & 5 \\
\hline Biaya & $\begin{array}{l}\text { Kapasitas } 6 \\
\text { mgd (1136.9 } \\
\left.\mathrm{m}^{3} / \mathrm{jam}\right), \text { kapital } \\
\text { dan produk } \\
\text { sebesar Rp } 1,1 \\
\text { trilliun dan Rp } \\
\text { Rp } 7.690,70 / \mathrm{m}^{3}\end{array}$ & $\begin{array}{l}\text { Kapasitas } 6 \\
\text { mgd (1136.9 } \\
\left.\mathrm{m}^{3} / \mathrm{jam}\right), \\
\text { kapital dan } \\
\text { produk } \\
\text { sebesar Rp } \\
540 \text { milliar } \\
\text { dan Rp } \\
7.242,95 / \mathrm{m}^{3}\end{array}$ & $\begin{array}{l}\text { Kombinasi RO-EDI } \\
\text { untuk kapasitas } 6 \\
\text { mgd ( } 1136.9 \\
\left.\mathrm{~m}^{3} / \mathrm{jam}\right) \text {, kapital dan } \\
\text { produk sebesar Rp } \\
155,2 \text { miliar dan } \mathrm{Rp} \\
6.979,57\end{array}$ \\
\hline Nilai & 5 & 15 & 30 \\
\hline $\begin{array}{l}\text { Kualitas } \\
\text { reject water }\end{array}$ & $\begin{array}{l}\text { Tidak dapat } \\
\text { dimanfaatkan, } \\
\text { mengandung } \\
\text { semua pengotor } \\
\text { air }\end{array}$ & $\begin{array}{l}\text { Dapat } \\
\text { dimanfaatkan }\end{array}$ & $\begin{array}{l}\text { Tidak dapat } \\
\text { dimanfaatkan, } \\
\text { mengandung } \\
\text { pengotor logam }\end{array}$ \\
\hline Nilai & 5 & 30 & 15 \\
\hline
\end{tabular}

kemudian dipompa menuju unit koagulasi dan flokulasi untuk pembubuhan kapur, sehingga kandungan logam pada air baku akan mengendap pada settling tank untuk mencegah terjadinya pengerakan pada membran. Setelah dari settling tank, air laut akan dialirkan menuju unit sand filter untuk mengurangi kekeruhan dan kandungan zat organik. Selanjutnya akan dialirkan menuju ke filter karbon aktif guna menghilangkan zat organik yang tersisa untuk mencegah terjadinya biofouling pada membran.

- Main Treatment

Air dikumpulkan di bak pengumpul sebelum dipompa menuju unit utama yaitu Reverse Osmosis. Proses ini berlangsung dalam 2 stage. Hal ini dikarenakan agar reject water yang dihasilkan tidak terlalu banyak, sehingga lahan yang dipergunakan untuk pengeringan garam tidak terlalu luas.

- Post-treatment

Proses terakhir pengolahan yaitu proses desinfeksi karena air produksi akan didistribusikan melalui pipa. Selain itu terdapat proses penambahan mineral pada air produksi dengan menambahkan nigari hasil dari produk sampingan SWRO, karena hasil dari SWRO adalah air demineralisasi (tanpa kandungan mineral).

\section{F. Perhitungan Hasil Produk Sampingan}

Tabel 4.

Kesetimbangan TDS pada Unit RO

\begin{tabular}{cccc}
\hline \hline Unit & $\%$ Removal & $\begin{array}{c}\text { Input } \\
(\mathrm{mg} / \mathrm{L})\end{array}$ & $\begin{array}{c}\text { Output } \\
(\mathrm{mg} / \mathrm{L})\end{array}$ \\
\hline RO stage 1 & $99.5 \%$ & 33960.0 & 169.8 \\
RO stage 2 & $99.5 \%$ & 33790.2 & 169.0 \\
\hline \hline
\end{tabular}

1) Garam Murni

Debit reject water yang akan dimanfaatkan menjadi garam murni adalah hasil dari reject water RO pada stage kedua, yaitu sebesar 35,1 L/detik atau 3032,64 $\mathrm{m}^{3} / \mathrm{hari}$. Kandungan garam pada reject water tersebut adalah 61,5 gram/liter. Produk garam yang dijual adalah garam dengan kualitas yang baik. Sebesar $90 \%$ untuk musim kemarau dan $50 \%$ pada saat musim hujan. Dengan hari kemarau

Tabel 5.

Mass Balance Total Pengotor (Kekeruhan, Zat Organik dan Logam)

\begin{tabular}{lccc}
\hline \multicolumn{1}{c}{ Unit } & \% Removal & $\begin{array}{c}\text { Input } \\
(\mathrm{mg} / \mathrm{L})\end{array}$ & $\begin{array}{c}\text { Output } \\
(\mathrm{mg} / \mathrm{L})\end{array}$ \\
\hline Filter intake & $30 \%$ & 31.9 & 22.3 \\
\hline Koagulasi + flokulasi & $0 \%$ & 22.3 & 22.3 \\
\hline Sedimentasi & $75 \%$ & 22.3 & 5.6 \\
\hline Pressure Sand Filter & $60 \%$ & 5.6 & 2.2 \\
\hline Karbon aktif & $98 \%$ & 2.2 & 0.0 \\
\hline
\end{tabular}

selama 183 hari dan hari hujan 182 hari. Produksi yang dihasilkan tiap tahunnya sebesar $38.067 .042 \mathrm{Kg} /$ tahun.

2) Nigari

Pada umumnya larutan tersebut memiliki ketebalan sebesar 3-5 cm dari kolam pengkristalan garam. Perencanaan ini diambil nigari dengan kedalaman $3 \mathrm{~cm}$. Sehingga produk nigari yang dihasilkan adalah 59.681.579 liter tiap tahunnya.

\section{G. Analisis Finansial}

1) Biaya Pengeluaran

- Biaya Investasi (RAB) 
Dihitung BOQ dan RAB untuk masing-masing unit pengolahan.

- Biaya Cicilan

$$
\text { Peminjaman }=60 \% \times \text { Rp107.942.114.817 }
$$

Tabel 6.

Rekapan Perhitungan RAB Tiap Unit

\begin{tabular}{cll}
\hline \hline No & \multicolumn{1}{c}{ Nama Unit } & \multicolumn{1}{c}{ RAB } \\
\hline 1 & Intake & Rp2.394.857.488 \\
2 & Flash Mix & Rp50.833.376 \\
3 & Slow Mix & Rp572.521.849 \\
4 & Sedimentasi & Rp603.866.462 \\
5 & Filter & Rp734.099.780 \\
6 & Bak Pengering & Rp288.590.644 \\
7 & Karbon Aktif & Rp591.333.635 \\
8 & Bak Pengumpul Ke Reservoar & Rp71.999.072 \\
9 & RO & Rp68.060.413.893 \\
10 & Bak Pengumpul Reject Water & Rp79.938.417 \\
11 & Bak Pengumpul Nigari Sementara & Rp3.921.864.584 \\
12 & Gudang Hasil Garam & Rp126.813.361 \\
13 & Pos Penjaga & Rp24.645.933 \\
14 & Kantor Administrasi & Rp115.313.196 \\
15 & Laboratorium & Rp137.667.359 \\
16 & Gudang B3 & Rp38.402.549 \\
17 & Gudang Alat & Rp20.647.255 \\
18 & Kloriator & Rp115.575.280 \\
19 & Reservoir & Rp2.311.004.442 \\
20 & Atap Tambak & Rp27.681.726.240 \\
& & Rp107.942.114.817 \\
\hline \hline
\end{tabular}

$\begin{aligned} & =\operatorname{Rp} 64.765 .268 .890 \\ \mathrm{~A} / \mathrm{P} & =\left[\frac{i(1+i)^{N}}{(1+i)^{N}-1}\right] \ldots \ldots \ldots \ldots \ldots \ldots . .(2) \\ \mathrm{A} / \mathrm{P} & =\left[\frac{12,5 \%(1+12,5 \%)^{10}}{(1+12,5 \%)^{10}-1}\right] \\ \mathrm{A} / \mathrm{P} & =0,18 \\ \mathrm{~A} & =0,18 \times \mathrm{Rp} 64.765 .268 .890 \\ & =\operatorname{Rp} 11.698 .018 .274\end{aligned}$

Sehingga, total cicilian yang harus dibayar adalah jumlah dari cicilan induk yaitu sebesar Rp11.698.018.274.

- Biaya Operasional dan Pengelolaan Limbah B3

Total biaya operasional 10 tahun perencanaan adalah Rp18.926.378.866 dengan rata-rata tiap tahunnya adalah Rp1.892.637.887. Sedangkan biaya pengelolaan limbah B3 sebesar Rp 84.670.472.831,09 tiap tahun dengan pembuangan lumpur B3 sebanyak $46 \mathrm{~m}^{3} /$ hari.

- Biaya Listrik, Sewa dan Gaji Karyawan

Total daya listrik yang dikonsumsi sebesar 1037,04 kW dengan rata-rata biaya tiap tahunnya adalah Rp42.311.017.634. Biaya sewa untuk tambak garam $10 \mathrm{Ha}$ selama 10 tahun adalah Rp 1.071.577.554,24 dengan ratarata biaya tiap tahunnya adalah $\mathrm{Rp} 510.275 .025,83$. Sedangkan untuk gaji karyawan mengalami kenaikan $1 \%$ tiap tahunnya. Sehingga total gaji karyawan selama 10 tahun sebesar Rp290.257.533.

2) Biaya Pemasukan

- Air Produksi
Debit air hasil produksi dari hasil pengolahan akan dikomersilkan sebesar $50 \mathrm{~L}$ detik. Biaya air produksi adalah $\mathrm{Rp} 2.000,00$ per $\mathrm{m}^{3}$. Sehingga total pemasukan tiap tahunnya sebesar Rp3.153.600.000.

- Garam Murni

Produksi garam tiap harinya adalah $148.873,84 \mathrm{~kg} / \mathrm{hari}$. Pendapatan tiap tahunnya sebesar Rp38.067.042.462

- Nigari

Produksi nigari tiap harinya adalah 241.920 liter. Pendapatan tiap tahnnya sebesar Rp89.522.368.795.

3) Net Present Value (NPV)

Berdasarkan persamaan 3 didapat hasil NPV selama tahun rencana proyek. Aliran kas didapat dari selisih pemasukan dan pengeluaran tiap tahunnya yang diakumulasi sampai akhir tahun akhir proyek.

Sehingga, NPV yang didapat sebesar Rp11.953.760.829. Karena NPV >0 sehingga proyek ini dapat dikatakan layak dijalankan.

4) Internal Rate of Return (IRR)

Bedasarkan persamaan 4, didapat nilai $(\mathrm{P} / \mathrm{F}, \mathrm{i} \%, 10)$ adalah 0,0808 . Nilai i\% didapat dari interpolasi persamaan 5 . Sehingga, didapat pada i\% sebesar $28,81 \%$ menghasilkan

Tabel 7.

Tabel Perhitungan Present Value

\begin{tabular}{cccc}
\hline \hline $\mathbf{t}$ & Aliran Kas (Rt) & $\mathbf{( 1 + i )}^{\mathbf{t}}$ & PV \\
\hline 0 & $-\mathrm{Rp} 107.942 .114 .817$ & & $-\mathrm{Rp} 107.942 .114 .817$ \\
1 & $-\mathrm{Rp} 89.138 .022 .076$ & 0,889 & $-\mathrm{Rp} 79.233 .797 .401$ \\
2 & $-\mathrm{Rp} 67.082 .272 .101$ & 0,790 & $-\mathrm{Rp} 53.003 .276 .722$ \\
3 & $-\mathrm{Rp} 46.529 .495 .878$ & 0,702 & $-\mathrm{Rp} 32.679 .152 .112$ \\
4 & $-\mathrm{Rp} 27.644 .913 .403$ & 0,624 & $-\mathrm{Rp} 17.258 .583 .341$ \\
5 & $-\mathrm{Rp} 10.611 .914 .024$ & 0,555 & $-\mathrm{Rp} 5.888 .858 .384$ \\
6 & $\mathrm{Rp} 4.365 .945 .174$ & 0,493 & $\mathrm{Rp} 2.153 .590 .580$ \\
7 & $\mathrm{Rp} 17.062 .721 .163$ & 0,438 & $\mathrm{Rp} 7.481 .361 .433$ \\
8 & $\mathrm{Rp} 27.227 .622 .784$ & 0,390 & $\mathrm{Rp} 10.611 .811 .957$ \\
9 & $\mathrm{Rp} 34.582 .277 .722$ & 0,346 & $\mathrm{Rp} 11.980 .664 .102$ \\
10 & $\mathrm{Rp} 38.817 .698 .872$ & 0,308 & $\mathrm{Rp} 11.953 .760 .829$ \\
\hline \hline
\end{tabular}

$\mathrm{P} / \mathrm{F}$ sebesar 0,0808. Hasil tersebut $>$ dari MARR (bunga bank $=12,5 \%)$. Sehingga proyek ini dikatakan layak dijalankan.

5) Payback Period

Payback period dapat dilihat pada saat aliran kas menjadi positif (tabel 7). Itu artinya, tahun tersebut telah menghasilkan keuntungan. Payback period jatuh pada tahun ke-6 dengan laba pada tahun tersebut adalah Rp2.153.590.580.

\section{KESIMPULAN/RINGKASAN}

Kesimpulan dari perencanaan ini adalah:

1) Berdasarkan hasil uji kualitas air baku di Pantai Kenjeran, Kota Surabaya parameter yang memenuhi adalah suhu $31^{\circ} \mathrm{C}$, kadar kadmium 0,0014 ppm dan $\mathrm{pH}$ yaitu 7,78 . Sedangkan parameter lain tidak memenuhi adalah kekeruhan sebesar 12 NTU, TDS sebesar 33960 ppm, salinitas 23,9 gram/L, TOC sebesar 0,387 ppm dan timbal sebesar 1,287 ppm.

2) Terdapat 3 alternatif yang dapat digunakan untuk 
pengolahan air laut, yaitu Multistage Flash Distillation (MSF), Reverse Osmosis (RO) dan Electrodeionization (EDI). Perencanaan ini memilih Reverse Osmosis (RO) sebagai teknologi yang terpilih. Karena biaya yang mahal untuk desalinasi dapat ditutupi dengan hasil jual reject water yang dimanfaatkan sebagai produk garam murni dan air nigari.

3) Perencanaan ini terdiri dari intake, bangunan koagulasiflokulasi, sedimentasi, unit filter, karbon aktif, unit RO, klorinator dan reservoir dengan tangki mineralisasi. Harga membran dan kebutuhan listrik yang mahal dapat ditutupi dengan uang pemasukan dari produk sampingan RO. Produk yang dihasilkan adalah garam murni dan air nigari. Secara ekonomis perencanaan ini dikatakan layak karena memiliki nilai NPV bernilai positif sebesar Rp11.953.760.829 dengan IRR sebesar 28,81\% yang lebih besar dari MARR Bank BNI yaitu 12,5\% dengan periode pengembalian setelah 6 tahun proyek berjalan berdasarkan metode payback period.

\section{UCAPAN TERIMA KASIH}

Penulis N.L.H. mengucapkan terima kasih kepada Bapak Prof. Ir. Wahyono Hadi, M.Sc., Ph.D. selaku dosen pembimbing yang telah membimbing, memberi masukan dan menyemangati dalam penyusunan laporan ini serta temanteman angkatan 2012 Teknik Lingkungan FTSP ITS yang juga telah saling memberikan dorongan semangat.

\section{DAFTAR PUSTAKA}

[1] P. Salanto, "Surabaya property market report". Research\&Forecast Report, 2H (2014). Hal. 9-11.

[2] Badan Pusat Statistik. "Surabaya dalam angka". 2015. hal 274.

[3] I.E. Fitra."PDAM Surabaya keluhkan air baku, tak tahu mengadu ke mana", http://surabaya.tribunnews.com/2015/06/03/pdam-surabayakeluhkan-kualitas-air-baku-tak-tahu-mengadu-ke-mana?page=2 (2015).

[4] P. Riski. "Pemkot Surabaya minta Kementerian PU bangun pintu air untuk atasi krisis air minum", < http://www.voaindonesia.com/content/pemkot-surabaya-mintakementerian-pu-bangun-pintu-air-untuk-atasi-krisis-airminum/2860933.html> (2015).

[5] N.I. Said. "Pengolahan payau menjadi air minum dengan teknologi Reverse Osmosis". Jakarta (2010).

[6] I.N. Pujawan, "Finasial teknik". Surabaya : Guna Widya (2009).

[7] P.H. Gleick,. "The biennial report on freshwater resources". The World's Water 2006-2007. Island Press, Chicago (2006). Vol 10 (3), 129.

[8] N.I. Said. "Aplikasi teknologi osmosis balik untuk memenuhi kebutuhan air minum di kawasan pesisir atau pulau terpencil". Kelompok Teknologi Pengelolaan Air Bersih dan Limbah Cair. BPPT (2003).

[9] S.A. Ibrahim, "A Comparative study of RO and MSF desalination plants. Desalination (1996). Vol 106, 99-106.

[10] M.A. Darwish,. "Critical comparison between energy consumption in large capacity Reverse Osmosis (RO) and Multistage Flash (MSF) seawater desalting plants". Desalination (1987). Vol 63, 143-161.

[11] A.D. Khawaji, I.K. Kutubkhanah dan J.M. Wie, "Advances in Seawater Desalination Technologies". Desalination (2008). Vol. 221, 47-69.

[12] M.C. Mickley, "Review of concentrate management options, ground water report 363". Technical Papers, Case Studies and Desalination Technology Resources. In: The Future of Desalination in Texas. Texas Water Development Board (2004). Vol. 2

[13] F. Reverberi, A. Gorenflo,. "Three year operational experience of a spiral-wound SWRO system with a high fouling potential feed water". Desalination (2007). Vol 203 (1-3), 100-106.
[14] J. Wood, J. Gifford, J. Arba dan M. Shaw,. "Production of ultrapure water by continuous electrodeionization". Desalination (2010). Vol 250 (3).

[15] V.I. Fedorenko, "Ultrapure water production by continuous electrodeionization method: technology and economy". Pharmaceutical Chemistry Journal (2002). Vol 38(1).

[16] P.H. Brian, R.,H. Zanapalidou, Zhang Li., K.J, Sims, dan L.R. Siwak, "Electrodeionization in power plant applications". Annual Meeting International Water Conference Pittsburg.Pittsburg (2005).

[17] I.G. Wenten, Khoiruddin, F. Arfianto, dan Zudiharto. "Bench scale electrodeionization for high pressure boiler feed water". Desalination (2013). Vol 314 